\title{
Early Experience of Percutaneous Transhepatic Biliary Stenting in Malignant Biliary Obstruction in Nepal
}

\author{
Thapa A, Suwal S, Chataut D, Subedi K \\ Department of Radiology and Imaging, TU Teaching Hospital, Maharajgunj, Kathmandu, Nepal \\ Received: October 15, 2018 \\ Accepted: November 10, 2018 \\ Published: December 30, 2018 \\ Cite this paper: \\ Thapa A, Suwal S, Chataut D, Subedi K. Early experience of percutaneous transhepatic biliary stenting in malignant \\ biliary obstruction in Nepal. Nepalese Journal of Radiology 2019;8(12):2-7. https://doi.org/10.3126/njr.v8i2.22966
}

\begin{abstract}
Introduction: Percutaneous biliary stenting is recommended for palliation of unresectable malignant biliary obstruction with short life expectancy. Percutaneous biliary stenting is newer interventional imaging guided procedure being practiced in Nepal. Aim of this study is to share our early experience of percutaneous biliary stenting and its complications in Nepal.
\end{abstract}

Methods: Retrospective review of clinical success, complication, stent patency and survival was done in 31 patients with nonoperable malignant biliary obstruction who underwent percutaneous transhepatic metallic biliary stenting from August 2016 to July 2018

Results: We successfully stented 31 malignant biliary obstructions, following external biliary drainage via sonography and fluoroscopy guidance, one week prior to the stenting. The patients were followed up for documentation and management of any complications related to the procedure. Cent percent reduction in bilirubin levels $<50 \%$ after 2 weeks were achieved. Procedure related mortality was nil. Major complications including early stent block were seen in 7 patients, which we managed accordingly. Stent patency rate for 3 months was $73 \%$ and for 6 months was $45 \%$. Although the procedure is recommended in short life expectancy patients, average survival of the patients in our experience was 7.1 months after the procedure with 2 of the patients survived $>12$ months after the procedure.

Conclusion: Percutaneous biliary stenting is less invasive palliation for unresectable malignant biliary obstruction with less complication as well.

Key words: Biliary Tract; Cholestasis; Fluoroscopy

\section{INTRODUCTION}

Malignant biliary obstruction has higher prevalence in Asian countries. Unfortunately,

Correspondence to: Dr. Sundar Suwal

Assistant Professor

TU Teaching Hospital

Maharajgunj Medical Campus

Maharajgunj, Nepal

Email:s1suwal@gmail.com these lesions are diagnosed at unresectable late stage. Thus, palliative treatment is the only option in most of the malignant biliary obstruction at the time of diagnosis. Besides 
pain relief, restoration of biliary drainage to gut is one of the important parts of palliative treatment. ${ }^{1,2}$ Cholangitis and intractable pruritus as complications of malignant biliary obstruction are considered definite indications for palliation. ${ }^{2}$ Three main treatment modalities for optimal biliary drainage are being used these days - endoscopic biliary stenting, percutaneous transhepatic biliary drainage and surgical biliary bypass. The choice among these treatment modalities depends on multiple factors, including availability of these services. ${ }^{2,3}$

Although mortality after surgical palliative biliary bypass has been low in recent studies, first choice of palliative biliary drainage for patients with short life expectancy is still nonsurgical biliary stenting. ${ }^{4,5,6}$ Also, non-surgical biliary stenting can be performed as an adjunct to pre-operative procedures. Among non-surgical biliary stenting, percutaneous techniques have advantage of selective lobar drainage and can be done with minimal sedation. ${ }^{1}$

Percutaneous biliary drainage has been practiced in Nepal for decades. However, percutaneous biliary stenting is being a recent upgrade in the percutaneous technique of biliary drainage in Nepal. No literature is available till date regarding experience of percutaneous biliary stenting in Nepal. Thus, our aim is to share our experience of percutaneous biliary stenting, including its complications, in a tertiary hospital of Nepal.

\section{METHODS}

Ethical clearance for the retrospective study was taken from ethical board of the hospital. In our study from August 2016 to July 2018, we have included 31 patients with nonoperable malignant biliary stricture due to cholangiocarcinoma, gall bladder carcinoma and pancreatic carcinoma who underwent percutaneous transhepatic metal stenting. All cases had INR less than 1.5, platelet more than 50,000 .
Non-operable surgical obstructive jaundice for palliative care who opted percutaneous metallic biliary stenting, underwent sonography and fluoroscopy guided percutaneous transhepatic external biliary drainage (PTBD), followed by catheter internalisation and infrapapillary selfexpanding metal stenting (SEMS, Honaro / Flex, CHM) through the PTBD access after a week. Stents with $10 \mathrm{~mm}$ diameter was used for single system stenting and that with $8 \mathrm{~mm}$ diameter were used when 2 stents were used. In case of type $3 \mathrm{a}$ stricture, one PTBD was internalized from right anterior to duodenum and one PTBD inserted from right posterior to left hepatic duct. Subsequently, criss cross biliary stenting done using $60 \times 8 \mathrm{~mm} / 10$ $\mathrm{mm}$ stent from right posterior to left hepatic duct and 120/100 x 8/10 mm stent deployed from right anterior to infrapapillary into the duodenum. External PTBD was left insitu till adequate expansion of SEMS indicated by development of pneumobilia. (Figure 1AD, 2). Periprocedural complications were noted. Pre biliary drainage serum bilirubin was compared to 2 weeks post stenting serum bilirubin. Patients were asked for follow up or telephonically asked for the health after 3 months, 6 months and 12 months.

\section{RESULTS}

Thirty one patients, 19 male and 12 female, were included in the study. Age of the patients ranged from 43 to 82 years with mean age of 58.5 years (Table 1). Ninteen were Cholangiocarcinoma, 8 were Gall bladder carcinoma and 4 pancreatic carcinoma. Fourteen were type I, 5 were type II, 8 were type IIIa Bismuth colerette malignant biliary stricture. Pruritis was relieved within few days of PTBD. Twenty three patients presented with pruritis, 10 were in cholangitis on presentation, whereas 8 presented just with jaundice. All cases were non-surgical candidate due to metastasis or vascular invasion. Eight patients were totally lost to follow up following the procedure. In rest of the patients mean bilirubin level of 19.5 was 
reduced to mean bilirubin level of 1.34 after 2 to 4 weeks of biliary stenting. Pruritis was resolved in all cases presented with pruritis. two patients were lost to follow up in between again. Eighteen of these patients survived for $>3$ months, 7 patients survived more than 6 months and 2 survived more than 12 months post-procedure with average survival of more than 7.1 months. Four of the patients were recently stented $(<3$ months).(Table 2) Survival time was shorter in cases with advanced disease in terms of biliary stricture, metastasis and associated other comorbidities. Except for the cases with periprocedure complications, average hospital stay was 4 days. Major post-procedural complications developed in seven patients (31\%), including early stent block in three patients. Arterial bleeding needing transcatheter embolisation of right hepatic artery was seen in 1 patient $(4.5 \%)$. Bile leak was seen in two patients (9\%). Pancreatitis developed in 1 patient (4.5\%). Infection developed in two patients $(9 \%)$. Early stent block seen in three patients $(13.5 \%)$. Three months stent patency was seen in 16 patients $(73 \%)$ and 6 months stent patency seen in 10 patients $(45 \%)$. No procedure related mortality was seen in our series (Table 3 ). In patient with type 3a stricture with criss cross biliary stenting, in which 60x8 mm stent was deployed from right posterior sectoral duct to left hepatic duct and 120x8 mm developed mild pancreatitis on two day of stenting. Pancreatitis settled down on medical management, however after 7 months he presented with Cholangitis. USG showed dilated right sided ducts with sludge and perihepatic collection which was aspirated for culture. Subsequently he developed biliary cutaneous fistula and was kept on stoma bag for 3 months. Again he presented with stent block, cholangitis and cholangiolar abscess. This time in stent left to right PTBD was placed. In 2 patients with periampullary carcinoma patient presented with jaundice after 2 months of stenting, Intrahepatic Biliary Radicals (IHBR) were dilated. One patient was managed with external PTBD and another with in stent biliary stenting.
One patient with type IIIa biliary stricture post criss cross biliary stent with stents of different radial force, the weaker stent failed to expand as compressed by expanded stronger stent. Balloon dilatation and in stent stenting of the weaker stent was done for adequate drainage. One patient with type 3 a stricture with 2 system. Biliary stenting presented with stent block and cholangiolar abscess on $4^{\text {th }}$ month of stenting. One patient with type II hilar cholangiocarcinoma with atrophic left lobe, biliary stenting was done from right posterior access. She developed cholangitis. PTBD done from left approach relieved cholangitis. After a year she developed stent block.

In one patient with perihilar cholangiocarcinoma, there was biloma formation after removal of external PTBD. It was managed with percutaneous drainage. Bile leak was concealed in few days.

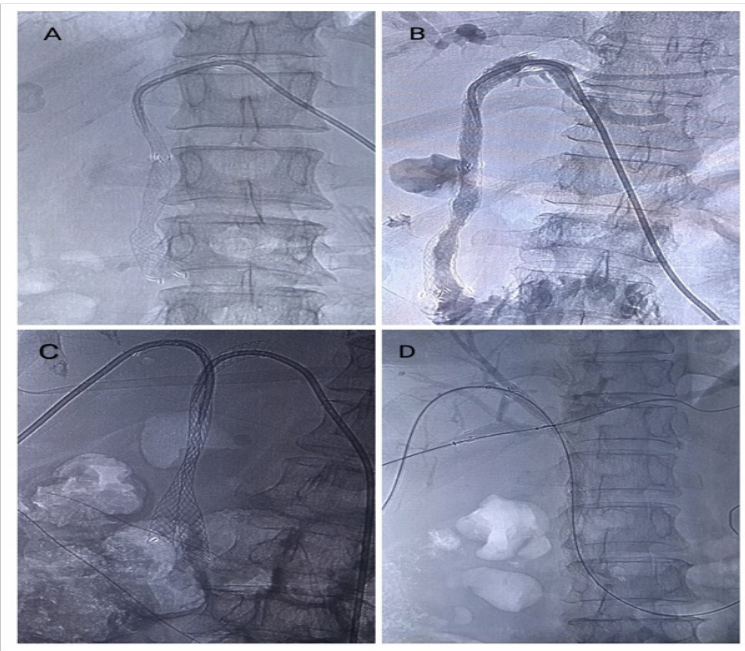

Figure 1: A. Single system biliary stenting for type 3 a cholangiocarcinoma from segment III approach. B. Single system biliary stenting in non-operable gall bladder carcinoma obstruction at common hepatic duct level. Good flow of contrast into the duodenum seen after stenting. $C$. Bilateral metal stenting for type 2 hilar cholangiocarcinoma. D. Criss-cross biliary stenting for type $3 \mathrm{~A}$ cholangiocarcinoma. Two stents deployed, $60 \mathrm{mmxl0} \mathrm{mm}$ stent from right posterior sectoral duct to left hepatic duct and 120x 10 $\mathrm{mm}$ stent from right anterior sectoral duct to duodenum. 


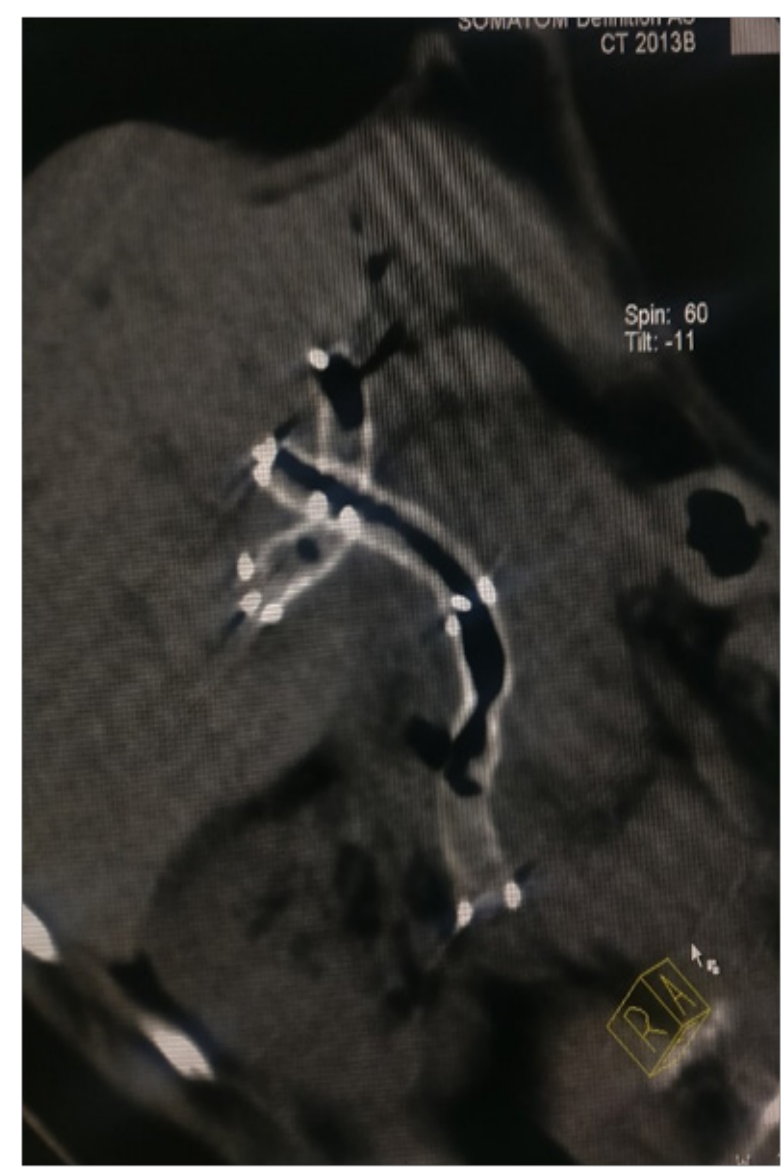

Figure 2: Oblique coronal MIP CT image showing well expanded self expanding metal stent in criss cross biliary stenting. Exuberant pneumobilia seen within the stent and intra hepatic bile ducts.

Table 1: Demographics of patients undergoing percutaneous biliary stenting $(n=31)$

\begin{tabular}{|l|l|}
\hline Male & 19 \\
\hline Female & 12 \\
\hline Age range & 43 years -82 years \\
\hline Mean age & 58.5 years \\
\hline
\end{tabular}

\section{Table 2: Post biliary stenting survival status}

\begin{tabular}{|l|l|}
\hline Lost to follow up & 10 \\
\hline On follow up $<3$ months & 4 \\
\hline Survival $>3$ months & 8 \\
\hline Survival $>6$ months & 7 \\
\hline Survival $>12$ months & 2 \\
\hline
\end{tabular}

Table 3: Procedure related complications encountered in our experience

\begin{tabular}{|l|l|}
\hline Bleeding & 1 \\
\hline Infection & 2 \\
\hline Bile leak & 2 \\
\hline Pancreatitis & 1 \\
\hline Early stent block $<2$ months & 3 \\
\hline
\end{tabular}

\section{DISCUSSION}

Palliation is the only option left in most of the malignant biliary obstruction. Palliation is done for pain alleviation, pruritus, cholangitis, or in cases to initiate chemotherapy or intrabiliary brachytherapy. Palliation has evolved with time with improvisation of various existing techniques that not only increase survival rate, but also improve their quality of life..$^{2,3,7,8}$

Decompression of dilated bile ducts via percutaneous transhepatic technique was reported by Kaude et $\mathrm{al}^{9}$ in 1969. Molnar et $\mathrm{al}^{10}$ reported a new therapeutic method to relief obstructive jaundice through percutaneous transhepatic catheter in 1974. Percutaneous metallic stenting are now being increasing used for palliation of malignant biliary obstruction. ${ }^{11}$ However, debate still exists regarding surgical bypass versus biliary stenting for these biliary obstructions. Even, debate exists for endoscopic biliary stenting against percutaneous biliary stenting. However, current recommendations for biliary drainage in palliative care in inoperable malignant proximal biliary obstruction with short life expectancy are percutaneous metallic biliary stenting. ${ }^{3}$ Also, it is easier to use the percutaneous biliary stenting as compared to endoscopic stenting. ${ }^{12}$ Longer patency rates of metallic stents over plastic stent are seen in many studies. ${ }^{3,13}$ Percutaneous biliary stenting is relatively new upgrade in palliation of biliary obstruction in Nepal. Our early experience showed very good results in term of palliation of symptoms related to biliary obstruction. 
We had cent percent technical success in our study, higher than that of similar experience of Kronsten et al ${ }^{14}$ and Haq et al. ${ }^{15}$ We could reduce bilirubin to $>50 \%$ in all the cases as compared to $68.2 \%$ only in the same study by Kronsten et al. ${ }^{14}$ Similar findings was seen in the experience of Haq et al. ${ }^{15}$ Complication rate in our study was similar to the study by Kronsten et $\mathrm{al}^{14}$ but less as compared to the experience of Haq et al. ${ }^{15}$ Thirty day mortality was nil in our study as compared to $28.8 \%$ in the study of Kronsten et $\mathrm{al}^{14}$ and $5 \%$ in the study of Haq et al. ${ }^{15}$

Mean survival rate in our study was 7.1 months, which is significantly higher than that of similar experience of Langman et $\mathrm{al}^{16}$, Kasuga et $\mathrm{al}^{17}$, Iwasaki et $\mathrm{al}^{18}$ and Haq et al. ${ }^{15}$ Early stent patency rate in our study is similar to that of study done by Liet al ${ }^{12}$, however, 6 month stent patency rate was slightly lower in our study (45\% vs 53\%). We are still following up the patients, and some of the procedures are done $<3$ months back. This could be the reason of lesser 6 months stent patency rate in our experience.

The results in our experience are very encouraging. However, our study has limitations as well. We had small sample size and high lost to follow up rate. Also, few of the procedures are still under follow up to assess procedure related complications and stent patency rate. Still, these procedures have increased the level of palliative care in malignant biliary obstruction and increased quality of life of patients with these biliary obstructions. This study includes our early experience in the field of percutaneous biliary stenting in Nepal. However, study in larger cohort could help us detecting the factors associated with the complications including stent occlusion. Then we can improvise our technique accordingly with even better results.

\section{CONCLUSION}

Percutaneous transhepatic metallic biliary stenting is minimally invasive very promising technique with less complication for the palliative care in patients with unresectable tumor causing biliary obstruction. Percutaneous technique is recommended for unresectable tumor causing proximal biliary obstruction with short life expectancy.

\section{CONFLICT OF INTEREST}

None

\section{SOURCES OF FUNDING}

None

\section{REFERENCES}

1. Goenka MK, Goenka U. Palliation: hilar cholangiocarcinoma.

World J Hepatol 2014;6(8):559. https://doi.org/10.4254/wjh.v6.i8.559

2. Van Delden OM, Lameris JS. Percutaneous drainage and stenting for palliation of malignant bile duct obstruction. Eur Radiol 2008;18(3):448-456. https://doi.org/10.1007/s00330-0070796-6

3. Chandrashekhara SH, Gamanagatti S, Singh A, Bhatnagar S. Current status of percutaneous transhepatic biliary drainage in palliation of malignant obstructive jaundice: a review. Indian $J$ Palliat Care 2016;22(4):378. https://doi.org/10.4103/0973$\underline{1075.191746}$

4. Witzigmann $\mathrm{H}$, Lang $\mathrm{H}$, Lauer H. Guidelines for palliative surgery of cholangiocarcinoma. HPB 2008;10(3):154-160.

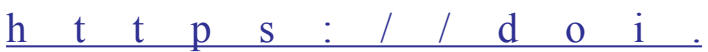
org/10.1080/13651820801992567

5. Lai EC, Chu KM, Lo CY, Fan ST, Lo CM, Wong J. Choice of palliation for malignant hilar biliary obstruction. Am J Surg 1992;163(2):208-212. https://doi.org/10.1016/00029610(92)90102-W 
6. Van-den-Bosch RP, Vander-Schelling GP, Klinkenbijl J, Mulder P, Van Blankenstein M, Jeekel J. Guidelines for the application of surgery and endoprostheses in the palliation of obstructive jaundice in advanced cancer of the pancreas. Ann Surg 1994;219(1):18-24. https://doi.org/10.1007/s00405-015$\underline{3550-8}$

7. Teixeira MC, Mak MP, Marques DF et al. Percutaneous transhepatic biliary drainage in patients with advanced solid malignancies: prognostic factors and clinical outcomes. $J$ Gastrointest Cancer 2013;44(4):398-403. https://doi.org/10.1007/s12029-013-9509-3

8. Covey AM, Brown KT. Percutaneous transhepatic biliary drainage. Tech Vasc Interv Radiol 2008;11(1):14-20. https://doi.org/10.1053/j.tvir.2008.05.003

9. Kaude JV, Weidenmier $\mathrm{CH}$, Agee OF. Decompression of Bile Ducts with the Percutaneous Transhepatic Technic. Radiology 1969;93(1):69-71. https://doi.org/10.1148/23.1.69

10. Molnar W, Stockum AE. Relief of obstructive jaundice through percutaneous transhepatic catheter-a new therapeutic method. Am J Roentgenol 1974;122(2):356-367. https://doi.org/10.2214/ajr.122.2.356

11. Rossi P, Bezzi M, Rossi $M$ et al. Metallic stents in malignant biliary obstruction: results of a multicenter European study of 240 patients. $J$ Vasc Interv Radiol 1994;5(2):279-285. https://doi.org/10.1016/S10510443(94)71483-4

12. Li M, Li K, Qi X et al. Percutaneous transhepatic biliary stent implantation for obstructive jaundice of perihilar cholangiocarcinoma: a prospective study on predictors of stent patency and survival in 92 patients. $J$ Vasc Interv Radiol 2016;27(7):1047-1055. https://doi.org/10.1016/j.jvir.2016.02.035
13. Wagner H, Knyrim K, Vakil N, Klose KJ. Plastic endoprostheses versus metal stents in the palliative treatment of malignant hilar biliary obstruction. A prospective and randomized trial. Endoscopy 1993;25(03):213-218. https://doi.org/10.1055/s-2007-1010295

14. Kronsten V, Speirs A, Ahmad F, Gibson M, Booth J, Chandra N. PWE220 Percutaneous transhepatic biliary drainage and stenting: a single centre experience. Gut 2015;64(1):A308. https://doi org/10.1136/ gutjnl-2015-309861.666

15. Haq T, Sanaullah M, Mohsin H, Sheikh MY, Ahmed B. Percutaneous transhepatic biliary stenting. $J$ Pak Med Assoc 2001;51(9):308-312. Available from: https://www.ncbi.nlm. nih.gov/pubmed/11715902 [Accessed 20th December 2018].

16. Langman EL, Suhocki PV, Hurwitz HI et al. Percutaneous biliary drainage catheter insertion in patients with extensive hepatic metastatic tumor burden. $J$ Gastrointest Oncol 2016;7(6):875-881. https://doi.org/10.21037/jgo.2016.06.13

17. Kasuga A, Ishii $H$, Ozaka $M$ et al. Clinical outcome of biliary drainage for obstructive jaundice caused by colorectal and gastric cancers. Jpn J Clin Oncol 2012;42(12):1161-1167. https://doi.org/10.1093/jico/hys168

18. Iwasaki M, Furuse J, Yoshino $M$ et al. Percutaneous transhepatic biliary drainage for the treatment of obstructive jaundice caused by metastases from nonbiliary and nonpancreatic cancers. Jpn J Clin Oncol. 1996;26(6):465-468. https://doi.org/10.1093/oxfordjournals. jico.a023265 